\title{
The Mutations of the Coronavirus - The Darker Perspective of the Future of the Current Coronavirus Epidemy Crisis Opinion
}

\author{
Shimon Shatzmiller* \\ Department of Biological Chemistry, Ariel University, Israel \\ *Corresponding Author: Shimon Shatzmiller, Department of Biological \\ Chemistry, Ariel University, Israeal.
}

Received: March 03, 2020

Published: April 09, 2020

(C) All rights are reserved by Shimon

Shatzmiller.

\begin{abstract}
Some tend to look at the currently vicious coronavirus pandemic crisis as an outbreak of a light disease, do not panic as an excuse but reality differs the current coronavirus roars without remedy or vaccine. It affects thousands all over the earth. In this opinion manuscript, we focus on the mutating virus and the spread via tubings. Sewage systems we hope that this information may contribute to the understanding of the currently roaring situation [1,2].
\end{abstract}

Keywords: Mutations; Coronavirus; Pandemic Crisis

DNA sleuths read the coronavirus genome, tracing its origins and looking for dangerous mutations [3]

Three more Corona patients were diagnosed in Israel, thus increasing to ten. An employee of the "Red Pirate" in Or Yehuda was contracted by the store manager who was also ill.

The other two returned from Italy last Thursday. The Ministry of Health said the three patients were suffering from minor symptoms and were to be hospitalized for isolation at Sheba Hospital in Tel Hashomer. Upon their transfer, Sheba will have 18 hospitalized in isolation - ten patients and eight passengers of the Corona Ship returning from Japan [4].

Director of the Sheba Corona complex: First death - a matter of time

The isolates are angry with them, the families move away from them, and the work in risky conditions grinds their nerves. This is what this week's tense routine of medical staff looks like for the sick and Corona carriers in Sheba. But the director of the compound, Dr. Gadi Segal, estimates that the evil is far ahead of us, and that the first death in Israel from the disease is only a matter of time. But I'm afraid this will happen very soon, and we're not prepared.

Reading the genome (made from RNA, not DNA) is also possible for Scholars to track the 2019-nCo V change and provide a roadmap for developing diagnostic and vaccine testing. "Genetics can tell us the real timing of the first cases" and whether they have occurred earlier than officials realized, molecular biologist Kristian said Andersen from Scripps research, a viral genome expert. "It can also tell us How did the outbreak start - from a single event of a virus moving from an infected animal to a human or many infected animals. Oh Genetics can tell us what strengthens the outbreak - a new introduction to it Animals or human-to-human transmission".

Coronavirus virus in N.Y.: The Manhattan woman was first confirmed as a woman of the State of Israel in her 30s who traveled in Iran, became infected with the virus and is now isolated at home. Major General Andrew M. Cuomo yesterday confirmed the first case of the New York state of the coronary virus, saying a woman had contracted the virus while traveling in Iran and is now in New York City when she is sent to confinement in her home. In a statement, Governor Cuomo said in a statement, "The patient is suffering from respiratory symptoms, but is not in serious condition and has been in controlled condition since arriving in New York. The woman, who is in her late 30s, is in Manhattan, according to state officials. She returned from Iran last week and was examined after She went to a city hospital; since she stayed home, officials said [5].

OVID-19, the new coronavirus which has killed more than 2,000 people, may spread through feces, scientists believe [6]. 
As the virus is thought to have only come to the attention of health officials late last year, when working in a market in the Wuhan Chinese city of Hubei Province, experts are still working to understand how it is delivered.

More than 75,000 cases of the deadly virus - whose effects include fever, dry cough and shortness of breath - have been approved, mainly in China. It has spread to more than 25 countries and territories, including the United States, as shown below in the statistics of Statistics. The World Health Organization (WHO) claims the virus is spreading like other members of the coronus virus family, SARS and MERS, through drops from coughs and sneezes, close contact with others and contaminated surfaces. How dangerous is the new Corona virus? [7].

Based on the previously known properties of the new corona virus, it can be assumed that it may also have the potential to become more dangerous for humans through mutations.

The hospitals in this country are for a possible epidemic or even pandemic.

\section{Pandemic}

A pandemic is a widespread disease that affects entire countries or continents.

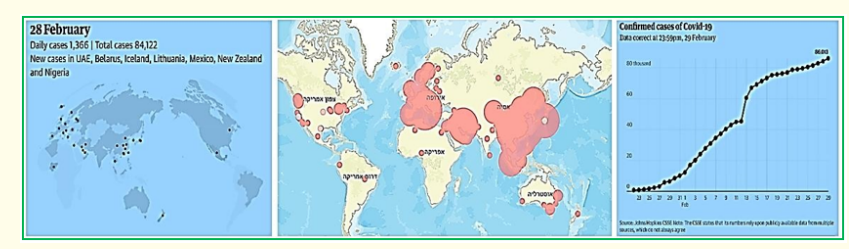

Figure 1: The Spread of coronavirus in the world 1 March 2020 [8].

The spread of corona in the world, which has also led to severe prevention measures in Israel, continues: The virus has reached all parts of the world except Antarctica, ad in the US fear of a global epidemic. The global outbreak situation.

But before the populists load their proof, we must see how our "populism president" handles all this. If the weakness of globalism is technocratic innocence, the glitches of populism are ignorance, incompetence and paranoia. Nothing about President Trump's response so far shows confidence that he is ready for the kind of crisis that candidate Trump was quick to acknowledge and exploit politically. And the fact that Roch Limbaugh spent yesterday stating that the virus is not worse than the cold, and that it is "kissed" by the press to "overthrow Donald Trump" - well, it does not give security to the right-wing pressure will force Trump to take the outbreak seriously....

The potential for CoVs to cause significant human disease is well demonstrated, with six known HCoVs-HKU1, OC43, NL63, 229E, SARS-CoV and MERS-CoV-causing colds, pneumonia, systemic infection, and severe or lethal disease [9]. Four of these viruses have been identified in just the last 10 years, with two, SARS-CoV and MERS-CoV, causing lethal respiratory and systemic infection [1,36]. Studies over the past decade have expanded the known phylogenetic, geographic, and species diversity of CoVs, and support multiple emergence events of CoVs into humans from bats and other zoonotic pools. The most recent evidence for CoV trans-species movement comes from the emergence of the novel MERS-CoV. From April 2012 to June 2013 MERS-CoV has caused 72 laboratory-confirmed cases and up to 50\% mortality from severe respiratory and systemic disease in at least 8 countries, with evidence for human-to-human transmission. MERS-CoV is most closely related to the bat CoVs HKU4 and HKU5, and the recently identified receptor dipeptidyl peptidase 4 (DPP4) is present on both human and bat cells, providing a compelling argument that zoonotic CoV infections resulting in severe human disease may be more frequent events than previously thought. Because of the lack of epidemiological data, it remains unknown whether multiple introductions from a zoonotic source or human transmission of a mild or asymptomatic disease is responsible for these continuing cases of sporadic severe infections. However, based on the high mortality rates associated with SARS-CoV and those reported for MERS-CoV, this novel virus potentially represents a serious threat to global health for which no vaccines or therapeutics currently exist.

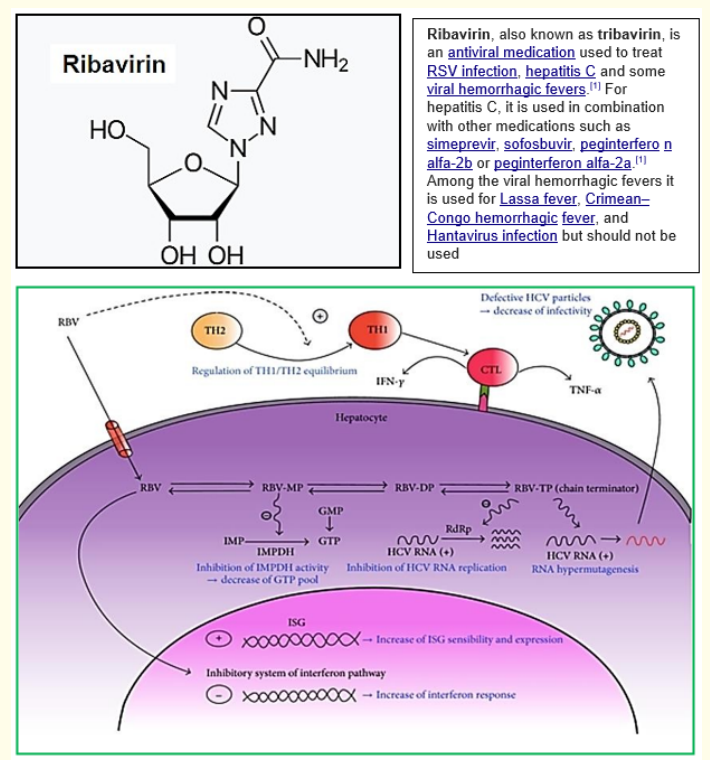

Figure 2 
The ribavirin carboxamide group can cause the natural nucleoside drug to resemble adenosine or guanosine, depending on its rotation. For this reason, when ribavirin is incorporated into RNA, as a base analogue of adenine or guanine, it aligns equally with either uracil or cytosine, resulting in mutations in RNA-dependent RNA replication in viral RNA. Such hyperemotion can be fatal to RNA viruses. Ribavirin (1- $\beta$-D-ribofuranosyl-1,2,4- triazole-3-carboxamide) is a guanosine nucleotide analogue and a broad spectrum direct antiviral agent (DAA). Ribavirin was discovered 30 years ago and is effective in vitro and/or in vivo against some RNA or DNA viruses [1-3]. This DAA is most commonly used to treat hepatitis $\mathrm{C}$ virus (HCV), severe human respiratory virus (RSV) infection, some blood fever, and more recently for immunosuppressed patients infected with hepatitis E virus (HEV) [4]. Based in part on the authors' work [5-13], this article focuses on the context of HCV infection in the ribavirin mechanism of action, its efficacy according to different therapeutic schedules, and its side effects and toxicity. Because clinical and pharmacological data indicate that adequate and early exposure to ribavirin improves the virologic response, the relevance of ribavirin drug monitoring in different patient populations and different therapeutic situations, including new promising treatment strategies, is also discussed.

While initial antiviral activity of RBV against CoVs was not mutagenic, ExoN2 CoVs treated with 5-FU demonstrated both enhanced susceptibility during multiplication, as well as decreased specific infection, consistent with 5-fluorouracil (5-FU); Functions as a mutagen. Comparison of next-generation and next-generation sequences of 5 FU-treated SARS-CoV populations revealed a 16fold increase in ExoN2 population mutations compared to ExoN. Ninety percent of these mutations represented transitions A: G and U: C, which correspond to the 5-FU combination during RNA synthesis. Together our results provide direct evidence that $\mathrm{CoV}$ ExoN activity provides a critical proofing function during virus replication. Furthermore, these studies identify ExoN as the first viral protein that differs from the RdRp that determines the susceptibility of RNA viruses to mutagens. Finally, our results show the importance of ExoN as a target for inhibition, suggesting that small molecule inhibitors of ExoN activity could potentially be Co-CoV therapy in combination with RBV or RNA polynomials [10-12].

Lethal mutagenesis is beyond the direction of virus extinction mediated by enhanced mutation rates during viral genome replication and is currently being investigated as a new antiviral potential strategy. Viral load and virus capacity are known to affect the extinction of the virus. Here we examine the effect or multiplicity of infection (MOI) on the progeny production of some RNA viruses under enhanced mutagenesis. The effect of basal mutant 5 -fluorouracil (FU) mutation on the replication of the rhinovirus chorionitis virus (LCMV) can also delay progeny production and ex- tinction of the virus in infections with high multiplicity of infection (MOI) or moderate titration without extinction in MOI. The effect of MOI is similar to the LCMV and vascular vesicular (VSV) virus, but minimal or absent to the oral and abdominal disease (FMDV) and encephalitis virus (EMCV). The increase in Shannon mutation frequency and entropy (mutant spectrum complexity) as a result of virus transfer in the presence of $\mathrm{FU}$, was more pronounced in low MOI for LCMV and VSV and high MOI for FMDV and EMCV. We present an extension of the deadly defection model that agrees with the experimental results.

Mutagenesis of Coronavirus nsp14 Reveals Its Potential Role in Modulation of the Innate Immune Response [13].

Coronavirus (CoV) non-structural protein 14 (nsp14) is a 60$\mathrm{kDa}$ protein encoded by the replicating gene that is part of the replication complex for replication. It is a bifunctional enzyme that carries activities $3=-5$ to $5=$ exoribonuclease (ExoN) and guanine-N7- methyltransferase (N7-MTase). ExoN exhaustive hydrolysis of single-stranded RNA and double-stranded RNAs (dsRNAs) and is part of a proofreading system responsible for the high fidelity of CoV replication. Nsp14 N7-MTase activity is required for viral mRNA cap synthesis and prevents the recognition of viral mRNA as "non-self" by the host cell. This work created a set of point mutations that affect different motifs in the nsp14 ExoN domain, using the transmitted gastroenteritis virus as a model for the Alphacoronavirus virus. ExoN inactivating mutants were not detectable even though they were competent in both viral RNA and protein synthesis. Specific mutation within zinc finger 1 (ZF-C) led to the production of a viable virus with growth and synthesis of viral RNA similar to that of parental virus. Motus recombinant transmitted gastroenteritis virus (TGEV) ZF-C (rTGEV- ZF-C) caused a decrease in cytopathic effect and apoptosis compared with the wild-type virus and a reduction in dsRNA accumulation levels at late post-infection. As a result, the mutant exerted a reduced antiviral response, which was confirmed by evaluating various steps in the dsRNA-induced antiviral pathway. Expression of beta interferon (IFN-), tumor necrosis factor (TNF), and interferon-stimulating genes in cells infected with rTGEV-ZF-C mutant was reduced compared with levels seen in parental virus. Overall, our data revealed a potential role for CoV nsp14 in modulating the innate immune response. The innate immune response is the first line of antiviral defense culminating in the synthesis of interferon cytokines and inflammatory tubes to control viral replication. CoVs have developed several mechanisms to counteract innate immune response at various levels, but the role of CoV-encoded ribonuclease in preventing antiviral response induced by dsRNA has not been described so far. Inserting a zinc finger 1 mutation into the nsp14 ExoN domain led to the production of a virus that caused a weak antiviral response, probably as a result of lower levels of dsRNA in the late stages of infection. These 
observations enabled us to propose a new role for CoV nsp14 ExoN activity against the antiviral response, which could serve as a new target for designing antiviral strategies.

A Japan travel guide recently released from a hospital after recovering from the coronav virus has tested positive again, reportedly [14]. The Osaka woman, in her 40s, was working on a bus with tourists from the Chinese focal point of Wuhan, after she was confirmed to be infected with the disease on Jan. 29, according to the Frank agency: e-Presse. The bus driver was diagnosed with the fatal illness. The woman was released from the hospital on February 01 and was tested for the virus five days later, though she still had a cough that disappeared a week later. But on February 21, she returned to the doctor because of a sore throat - the end was tested positive again on Wednesday. According to AFP, Judge Osaka said the case is the first of a person, Kerry. Positive for COVID-19 in Japan, after apparently being worried about it. Second role cases! China has already been reported, according to Reuters.

Nearly 2,800 people died from the disease, affecting some 80,000 people worldwide. Once you have the infection, it can remain dormant and with minimal symptoms, and then you can get muicel1 action if it finds its way to your lungs: Professor Philip Tyr, not from New York University School of Medicine, told Reuters. He said much was still unknown about COVID-19. I'm not sure it's two-dimensional, like anthrax. "he suggest to all the perplexed to read the professional literature on Corona and then maybe understand what is happening to the world. The virus is mutagenic and this explains how the "healed" are re-infected. Their immune system protects them from a virus that no longer exists. The virus changes every few hours. Well. The new patient, it is a mutant of the original virus. And that's the disease with her but a disease similar to the original infection. Really a devil.

With the new virus spreading from person to person (possibly including people without symptoms), arriving on four continents, and traveling faster than SARS, this seems a less likely cause.

It is still possible that closure and travel bans will first stop the outbreak and then eradicate the bacterium, and the world will never see the 2019-nCoV again, as World Health Organization epidemiologist Dr. Mike Ryan said Saturday. That's what happened with SARS this year 2003.

However, many experts see that the happy result is increasingly unlikely. Scientists at the University of Hong Kong concluded in an article in The Lancet last week, "Independent outbreaks [of 2019$\mathrm{nCoV}]$ in the world's largest cities can be unavoidable because of significant export of pre-symptomatic cases.
Researchers are therefore asking what a defeatist question looks like, but its answer has enormous implications for public policy: What will be the world with the endemic 2019- nCoV - which is permanently circulating in the human population? [15].

China officials knew of coronavirus in December, ordered a cover-up, report says [16].

Chinese scientists knew about the virus and its deadly effects as early as December - but government officials were forced to suppress the evidence, according to a report [17].

In late December, several genomic companies examined samples from sick patients in Wuhan - the coronavirus virus outbreak center - and noticed alarming similarities between their diseases and the SARS virus from 2002, London Times reported on the Chinese business news site Caixin Global.

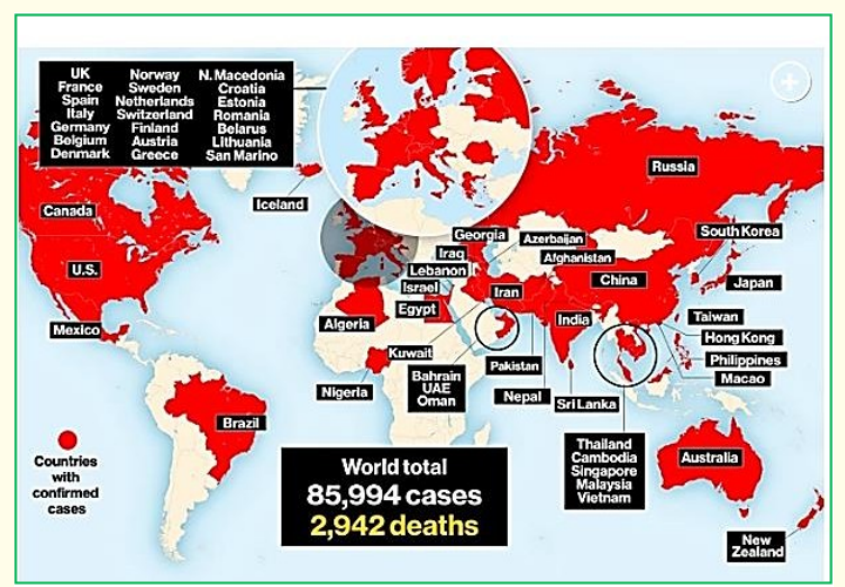

Figure 3

Investigators alerted Beijing to their findings - and on January 3, received a ban on publication from the National Health Commission of China, with instructions to destroy the specimens.

Instead of gobbling up the virus, Vaughan officials continued their annual Potok meal for 40,000 families.

The alleged cover-up continued when representatives from the US Centers for Disease Control and Prevention visited Wuhan Jan. 8 , where officials intentionally withheld information that hospital workers had been infected by patients - a telltale sign of contagion.

News of the virus' highly contagious nature didn't surface publicly until January 20 . Wuhan was locked down and a mass quarantine ordered three days later. 
SARS and plumbing: The role sewage plays in spreading disease

Recent World Health Organization (WHO) reports have shed new light on the role played by sewers in spreading the deadly illness known as severe acute respiratory syndrome, or SARS. The issue came up after the SARS outbreak in Hong Kong-based Amoy Garden Complex. SARS like the one in China, Americans can benefit from the information revealed by Hong Kong researchers to prevent the spread of severe and common illnesses in their home's plumbing [18].

How can the coronavirus spread through W.C. pipes? Experts are investigating in Hong Kong.

Fecal matter

The evacuation at Hong Mei House was a precaution [19].

While scientists are still exploring how the virus spreads, they believe it is transmitted primarily in direct contact, such as touching someone's hand, and through drops, for example, an infected person sneezes or coughs on someone else.

Therefore, the virus could spread through the block of flats through close human contact or the use of elevator buttons.

But since the two patients were living directly above each other, and on initial examination it was found that a pipe was disconnected from the bathroom waste pipe, authorities decided to investigate whether the virus could spread through the building's sewer system.

Ivan Hung, head of the Infectious Diseases Division at the University of Hong Kong, told.

CNN that early studies on Roman coronavirus have raised his stance on feces, although investigations are still ongoing to what extent the virus could be transmitted in this way. Microbiologist Yuan Kwok-Jung said at Tuesday's press conference that an improperly sealed tube could lead to virus transmission by carrying infected feces into the building's ventilation system and turning it into people's washrooms.

Yuan said that "the fecal duct is connected to the air duct, it is very likely that the stool virus will be transmitted through the air fan to the W.C.

Chinese researchers are pouring the innovative corona virus into the stool of infected people, which may help explain why it is spreading so fast.

The presence of live virus particles in faecal specimens suggests an oral fecal pathway for coronus virus, which may be why it caused outbreaks of powerful cruise ships, often seen with the gastrointestinal norovirus, which also spreads along this pathway. More than 600 Cubid-19 infections were confirmed among travelers and crew who boarded the Diamond Princess, the ship was arranged for two weeks in Yokohama, Japan.

The Chinese Center for Disease Control and Disease Prevention said that "this virus has many ways of transmission that can partially explain" its rapid spread.

\section{Concluding Remarks}

Coronavirus is a mutating virus. It may change its features while infecting humans. It is trafficking via sewage systems and air. Currently, no antiviral drug or vaccine can be applied as remedy.

\section{Bibliography}

1. Shimon Shatzmiller., et al. "Coronavirus in an Outbreak in China”. Acta Scientific Neurology 3.2 (2020): 1-4.

2. Sexton NR., et al. "Homology-based identification of a mutation in the coronavirus RNA-dependent RNA polymerase that confers resistance to multiple mutagens". Journal of Virology 90.16 (2016): 7415-7428.

3. DNA sleuths read the coronavirus genome, tracing its origins and looking for dangerous mutations (2020).

4. https://www.ynet.co.il/articles/0,7340,L-5687200,00. html\#autoplay

5. Coronavirus in N.Y.: Manhattan Woman Is First Confirmed Case in State.

6. Coronavirus May Be Spreading So Fast Because of Fecal Transmission, Scientists Say.

7. Wie gefährlich ist das neue Coronavirus?

8. https://www.mako.co.il/news-world/2020_q1/Article52bd4dbad858071027.htm?sCh=31750a2610f26110\&p Id $=350865906$

9. Everett Clinton Smith., et al. "Coronaviruses Lacking Exoribonuclease Activity Are Susceptible to Lethal Mutagenesis: Evidence for Proofreading and Potential Therapeutics". PLOS Pathogens 9.8 (2013): e1003565.

10. de la Torre JC. "Arenavirus extinction through lethal mutagenesis". Virus Research 107.2 (2005): 207-214.

11. Agudo R., et al. "Molecular characterization of a dual inhibitory and mutagenic activity of 5-fluorouridine triphosphate on viral RNA synthesis. Implications for lethal mutagenesis". Journal of Molecular Biology 382.3 (2008): 652-666. 
12. Moreno H., et al. "Mutagenesis-mediated virus extinction: virus-dependent effect of viral load on sensitivity to lethal defection". PLoS ONE 7 (2012): e32550.

13. Martina Becares., et al. "Mutagenesis of Coronavirus nsp14 Reveals Its Potential Role in Modulation of the Innate Immune Response". Journal of Virology 90.11 (2016) 5399-5414.

14. Experts envision two scenarios if the new coronavirus isn't contained.

15. Trey Gowdy demands China be held accountable for coronavirus.

16. How to stage a fake epidemic (and brainwash billions of people).

17. China officials knew of coronavirus in December, ordered cover-up, report says.

18. SARS and Plumbing: The Role Sewage Plays in Spreading Disease.

19. How can the coronavirus spread through bathroom pipes? Experts are investigating in Hong Kong (2020).

\section{Assets from publication with us}

- Prompt Acknowledgement after receiving the article

- Thorough Double blinded peer review

- Rapid Publication

- Issue of Publication Certificate

- High visibility of your Published work

Website: www.actascientific.com/

Submit Article: www.actascientific.com/submission.php

Email us: editor@actascientific.com

Contact us: +919182824667 